\title{
Natural convection heat transfer inside finned enclosure
}

\author{
Ra'ed Ahmed Ali \\ Assistant Lecture \\ Mosul University - Engineering College-Mechanical Engineering Department
}

\begin{abstract}
This work is focused on the numerical study of steady, laminar natural convection heat transfer in square enclosure with perfectly conducting thin fins. The fins are attached to both vertical surfaces, the two vertical surfaces are at different temperatures while the other two horizontal surfaces are insulated. In the formulation of governing differential equations, mass, momentum and energy equations are applied to the enclosure. To solve the governing differential equations a finite difference method is used. Three cases were studied in this work depending on the number of fins attached to vertical surface, (i) single fin (ii) two fins and (iii) three fins. The results presented for various Rayleigh number and dimensionless fins length ( in the range of $0.15,0.25,0.35,0.45$ ), in a form of streamlines, isotherm lines, as well as Nusselt number. It was observed that the increasing in Rayleigh number resulting in increase in Nusselt number and in the temperature gradient. Due to increasing in the in the dimensionless length and number of fins, it was observed that a decrease in temperature gradient and in the Nusselt number were occurred.
\end{abstract}

Key words : natural convection, enclosure, fins, heat transfer.

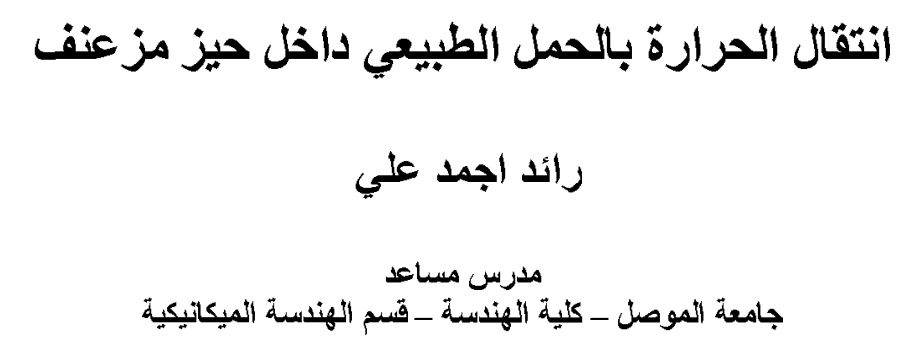

الخانلاصة

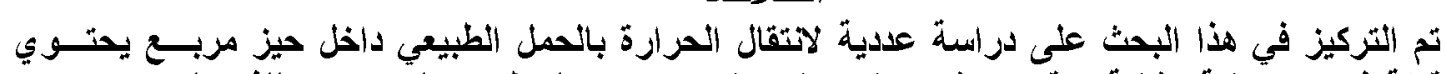

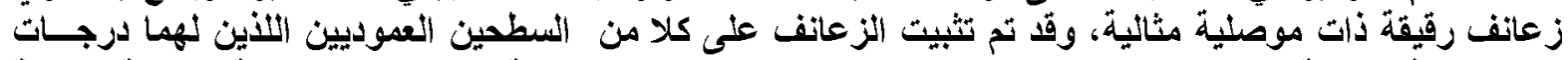

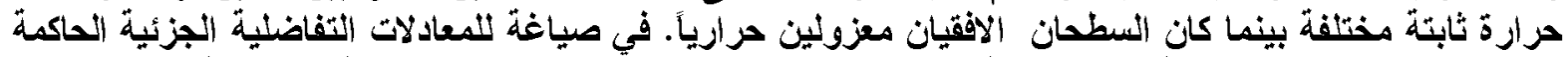

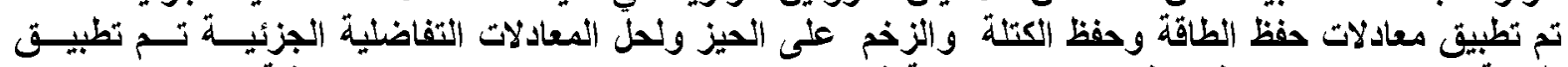

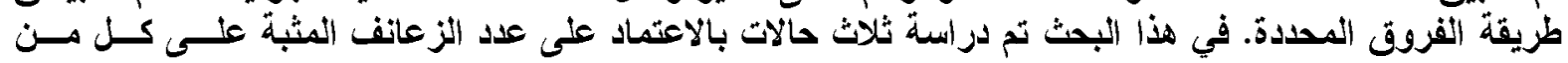

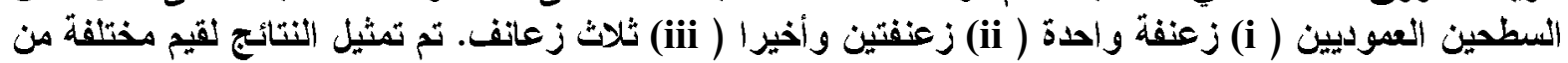

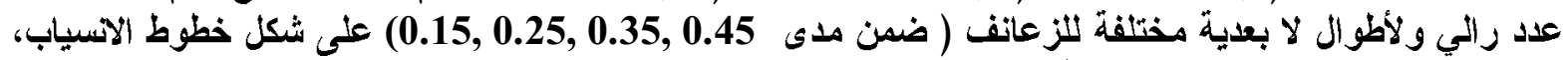

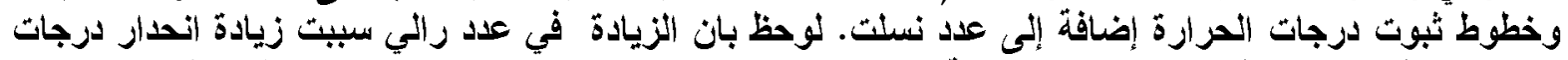

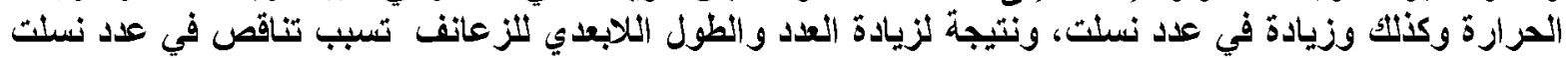
وانحداردرجات الحرارة.

الكلمات الدالة : الحمل الطبيعي، حيز ، زعانف ، انتقال الحرارة. 


\begin{tabular}{|c|c|c|c|}
\hline \\
\hline \multicolumn{4}{|c|}{$\begin{array}{l}\text { Nomenclature } \\
X \quad \text { Dimensionless horizontal distance }\end{array}$} \\
\hline$Y$ & Dimensionless horizontal distance & $\mathrm{u}$, & Velocity in $\mathrm{x}$-direction \\
\hline$\vartheta$ & Kinematics viscosity & $\mathrm{v}$ & Velocity in y-direction \\
\hline $\mathrm{Y}_{\mathrm{lf}}$ & fin height from horizontal surface & $\mathrm{x}$ & Horizontal distance \\
\hline $\mathrm{Y}_{\mathrm{f}}$ & Dimensionless fin height from horizontal surface & $f$ & Arbitrary function \\
\hline $\mathrm{L}_{\mathrm{f}}$ & Dimensionless fin length & $\mathrm{G}$ & Gravitational acceleration \\
\hline $\mathrm{L}$ & Horizontal/ vertical dimension of enclosure & $\mathrm{K}$ & Thermal conductivity $\mathrm{w} / \mathrm{m} \mathrm{K}$ \\
\hline$l_{f}$ & Fin length & $\mathrm{y}$ & vertical distance \\
\hline $\mathrm{Nu}$ & Nusselt number & $\phi$ & Dimensionless stream function \\
\hline $\mathrm{P}$ & Fluid pressure & $\omega$ & Vorticity \\
\hline$Q_{\text {cond }}$ & Heat transfer by conduction & $\Omega$ & Dimensionless Vorticity \\
\hline $\mathrm{Q}_{\text {conv }}$ & Heat transfer by convection & $\alpha$ & Thermal diffusivity \\
\hline $\mathrm{Ra}$ & Rayleigh number & $\beta$ & Thermal expansion coefficient \\
\hline Subsc & ipts & $\theta$ & Dimensionless temperature \\
\hline $\mathrm{H}$ & Hot & $\rho$ & density \\
\hline $\mathrm{C}$ & Cold & $\Psi$ & Stream function \\
\hline
\end{tabular}

\section{Introduction}

Due to its low cost and apparent simplicity, natural convection cooling or heating has always been an attractive technique in thermal engineering. The application in which it is used are countless, embracing many technical fields. Examples are energy storage systems, thermal control of electronic device and buildings. Such variety of applications has generated a large body of work that studied buoyancy driven flows in several configuration and different boundary condition[1].

A review of literature shows that there are various studies on natural convection in cavities containing fins that may classified into major categories: i) those in square and rectangular cavities containing one or more in tall cavities with fins attached to one active side. ii) Studies in tall cavities with fins attached to one active side forming open micro-cavities with various boundary conditions. The addition of fin or array of fins to the enclosure surface is the reliable method to increase the overall heat transfer rate between the heat dissipating surface and the heat absorbing surface. Accordingly, the study of natural convection from finned surface has been subject of many experimental and numerical investigations. These investigations recently have been motivated by the advance in the electronics technology and the need for reliable and efficient cooling techniques. The increase in heat transfer rate due to the presence of a fin or fins array depends greatly on the location, material and geometry of the fin.

Frederick [2] reported a parametric study of natural convection in an air-filled, differentially heated, inclined square cavity, with a fin attached perpendicularly to its cold wall at Rayleigh numbers of $10^{3}-10^{5}$ and partition relative lengths of 0.25 and 0.5 . It was reported that the fin causes convection suppression, and heat transfer reductions of up to $47 \%$ relative to the undivided cavity at the same Rayleigh number. Frederick and Valencia [3] considered heat transfer in a square cavity with a conducting partition at the center of its hot wall. They studied the impact of partition length and conductivity on heat transfer rate.. Scozia and Frederick [4] 
considered natural convection heat transfer in a differentially-heated slender rectangular cavity of aspect ratio of 20 with multiple conducting fins attached on the active cold wall of the cavity. They concluded that as the inter-fin aspect ratio was varied from 20 to 0.25 , the flow patterns evolved considerably and the average Nusselt number exhibited maximum and minimum values whose locations depended on the value of the Rayleigh number. Hasnaoui et al. [5] studied numerically a vertical rectangular differentially-heated enclosure with adiabatic fins attached to the heated wall. The enclosure aspect ratio was varied from 2 to 3, the dimensionless fin length from 0 to 0.75 , and micro-cavity height from 0.3 to 0.67 . Their study showed that the heat transfer through the cold wall was reduced compared to the case without fins and this reduction was enhanced with increasing fin length and decreasing Rayleigh number. Nag et al. [6] studied natural convection in a differentially heated square cavity with a horizontal partition plate on the hot wall. They analyzed the thermal effect of partition's length and location for Rayleigh number range from $10^{3}$ to $10^{6}$. Lakhal et al [7] Studied numerically the natural convection heat transfer in an inclined rectangular enclosure with perfectly conducting fins attached to the heated wall. The parameters governing this problem are Rayleigh number, Aspect ratio of the enclosures, dimensionless of the partition the inclination angle and Prandtl number. Useful Engineering correlation is derived for practical applications. Bilgen [8] studied natural convection in enclosures with partial partitions attached to the adiabatic horizontal surfaces. His study covered various geometrical parameters: enclosure aspect ratio , number of partitions, partitions dimensionless position, partitions dimensionless height $=0.0-0.15$, and Rayleigh number. The results showed that the flow regime was laminar for $R a$ up to $10^{8}$ thereafter turbulent. The heat transfer was reduced (a) when two partitions were used instead of one, (b) when the aspect ratio was made smaller, (c) when the position of partitions was farther away from the hot wall. Shi and Khodadadi [9] reported a detailed parametric study of flow and heat transfer in a lid-driven cavity due to the presence of a single thin fin. Three fins with lengths equal to 5, 10, and 15 percent of the side. They concluded that the fin slows the flow near the anchoring wall and reduces the temperature gradients, thus degrading heat transfer capacity. Shi and Khodadadi [10] also studied steady laminar natural convection within a differentially heated square cavity due to the presence of a single highly conductive thin fin. The study covered three fin lengths, seven fin locations, and $R a=10^{4}-10^{7}$. They have stated that for high Rayleigh numbers the flow field is enhanced regardless of the fin's length and position indicating that the extra heating mechanism outweighs the fin's blockage effect. They also reported that better heat transfer performance can be achieved if the thin fin attached to the hot wall was closer to the insulated walls. Belgen [11] In This work A numerical study has been carried out in differentially heated square cavities, which are formed by horizontal adiabatic walls and vertical isothermal walls. A thin fin is attached on the active wall. A parametric study is carried out using the following parameters: Rayleigh number, dimensionless thin fin length from 0.10 to 0.90 , dimensionless thin fin position from 0.0 to 0.90 , dimensionless conductivity ratio of thin fin. It is found that Nusselt number is an increasing function of Rayleigh number, and a decreasing function of fin length and relative conductivity ratio. There is always an optimum fin position, which is often at the center or near center of the cavity, which makes heat transfer by natural convection minimized. The heat transfer may be suppressed up to $38 \%$ by choosing appropriate thermal and geometrical fin parameters. Ben-Nakhi and Chamkha [12] who studied the effects of a heated thin fin length and inclination angle on steady, laminar, two-dimensional natural convection fluid flow inside a differentially-heated square enclosure. The study covered fin inclination angles from $0^{\circ}$ to $180^{\circ}$, and dimensionless fin lengths of $0.2,0.35$, and 0.5 . Abdullatif Ben-Nakhi et al [13] In This work is focused on the numerical study of steady, laminar, conjugate natural convection in a square enclosure with an inclined thin fin of arbitrary length. The inclined fin is attached to the left vertical thin side of the enclosure while the other three sides are considered to have finite and equal thicknesses of arbitrary thermal 
conductivities. The left wall of the enclosure to which the fin is attached is assumed heated while the external sides of the other three surfaces of the enclosure are cooled. The inclined thin fin is perfectly conductive and is positioned in the middle heated surface of the enclosure. Three different fin lengths equal to 20,35 and 50 percent of the heated surface are considered. Representative results illustrating the effects of the thin fin inclination angle and length and the thermal conductivity of the thick surfaces on the streamlines and temperature contours within the enclosure are reported. In addition, results for the local and average Nusselt numbers are presented and discussed for various parametric conditions. M. Ghassemi et al [14] Studied the effect of the inclination angle on flow field and heat transfer in differentially heated square cavity with two insulated baffles attached to its isotherms walls. The isotherms walls are at different temperature. The walls that make an angle $\varphi$ with the horizontal are adiabatic. It is observed that all baffles lengths and baffles positions when the $\varphi=90^{\circ}$ Nusselt number is almost minimum. In addition the Nusselt number decreases as baffle length increases, generally Finally it is shown that Nusselt number changes with baffles position. Sivasankaran et al [15]A numerical study has been performed to analyze the combined temperature and species gradients induced buoyancy-driven natural convection flow of cold water, near its density extremum, contained in a rectangular partitioned enclosure with isothermal side walls and insulated top and bottom. A highly conductive thin baffle is attached to the hot wall. The flow is assumed to be two-dimensional. Numerical solutions of the governing equations are obtained using the twostep ADI method coupled with the SOR technique.The results of the investigation are presented in the form of steady-state streamlines, isotherms, and isoconcentration lines. The results are discussed for different positions and lengths of the baffle and different values of Schmidt number and hot-wall temperatures. The heat and mass transfer rates calculated are found to behave nonlinearly. The average heat transfer rate is enhanced when the position of the baffle is raised. The heat and mass transfer are increased with increasing enclosure size. It is also found that the convective heat transfer is greatly influenced by the presence of a density maximum in the convective fluid. Feng Xu et al [16] Studied The unsteady thermal flow around a thin fin on a sidewall of a differentially heated cavity is visualized using a shadowgraph technique and measured using fast-response thermistors. Experiments show that the transition of the unsteady thermal flow around the fin from initiation by sudden heating to a quasi-steady state undergoes a number of stages including the formation of a horizontal gravity current under the fin and a starting plume bypassing the fin, entrainment into the downstream thermal boundary layer, and separation and oscillations of the thermal flow above the fin. It is found that the frequency of the oscillations is a linear function of the Rayleigh number. the effects of surface radiation and number of partitions on the heat transfer and flow structures in a rectangular enclosure, inclined by $\Phi=45^{\circ}$ with respect to the horizontal plane, have been studied numerically by Mohammed Rabhi et al [17]. The two vertical walls of the enclosure, of an aspect ratio equal to 4, are heated with uniform different temperatures, while the others are adiabatic. It was found that the total heat transfer in the enclosure is increased under thermal radiation heat flux and reduced significantly with increasing the number of partitions. N. Kasayapanand $*[18]$ presented Numerical modeling of the electric field effect on natural convection in square enclosures with single fin and multiple fins is investigated. The interactions between electric, flow, and temperature fields are analyzed using a computational fluid dynamics technique. The parameters considered are the supplied voltage, Rayleigh number, size of enclosure, electrode arrangement, number of fins, and fin length. It can be concluded that the flow and heat transfer enhancements are the decreasing function of Rayleigh number. Moreover, the heat transfer coefficient is substantially improved by the electric field effect especially at the high number of fins and long fin length. Surprisingly, the maximum average velocity and heat transfer enhancement occur at the different electrode arrangements for the single fin and multiple fins. 
The purpose of the present study is to investigate the effects of the perfectly conducting thin fins attached to both vertical hot and cold isotherms walls on natural convection in side enclosure. In three different cases relative to number of fins attached to hot \& cold walls equally spaced (i) one fin attached to each wall. (ii) two fins attached each wall. and (iii) three fins in each wall. The effect of the fin length, number of fins and Rayleigh number on fluid flow, isotherm lines and Nusselt number are studied for each on of the mentioned cases.

\section{Mathematical Model}

The physical system under consideration is a two dimensional square finned enclosure of length ( $\mathrm{L}$ ) filled with air. The vertical side walls of the enclosure are isothermal but maintained at different temperatures $T_{h}$ (hot wall) and $T_{c}$ (cold wall) with $T_{h}>T_{c}$. The horizontal walls are thermal insulated, very thin perfectly conducting fins at length $l_{\mathrm{f}}$ attached to the both vertical walls. As in fig. 1

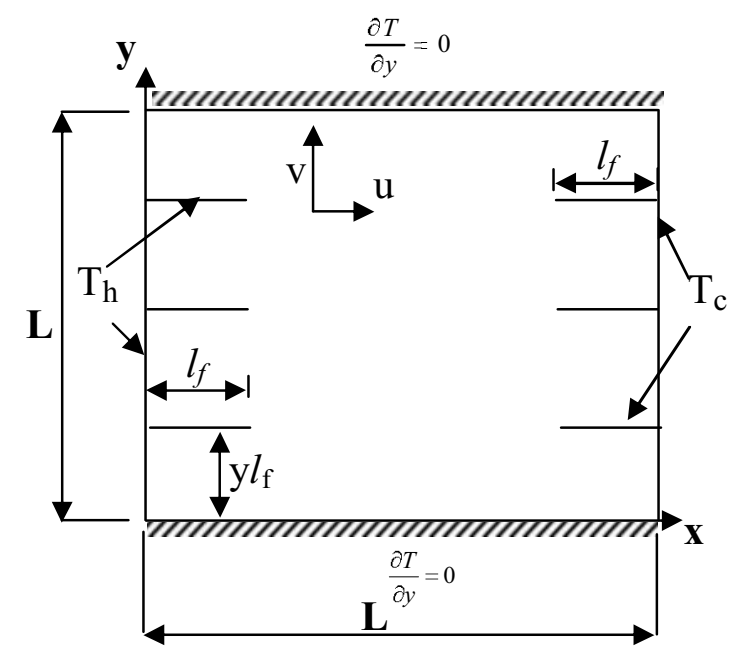

Fig. 1 Schematic of the Square cavity with thin Fins attached on Hot \& Cold walls

To simplify the analysis, the following assumptions are made:

1- The fluid is incompressible, steady and laminar.

2- A two-dimensional distribution of fluid flow and temperature.

3- There is no viscous dissipation.

4- The gravity acts in the vertical direction.

5- Fluid properties are constants and fluid density variations are neglected except in the buoyancy term (the Boussinsque approximation ).

6- Radiation heat exchanges is negligible.

The governing equations include the equations of the continuity, momentum and the energy. The equations are as follows.

1-The continuity equation for the steady and incompressible flow is given by: 


$$
\frac{\partial u}{\partial x}+\frac{\partial v}{\partial y}=0
$$

2-The following assumption, as steady flow, constant property of fluid \& and no heat generation are considered for the energy equation is:

$u \frac{\partial T}{\partial x}+v \frac{\partial T}{\partial y}=\alpha\left(\frac{\partial^{2} T}{\partial x^{2}}+\frac{\partial^{2} T}{\partial y^{2}}\right)$

3-The momentum equation in $\mathrm{x}$ and $\mathrm{y}$ direction are :

$$
\begin{aligned}
& u \frac{\partial u}{\partial x}+v \frac{\partial u}{\partial y}=-\frac{1}{\rho} \frac{\partial p}{\partial x}+\frac{\partial}{\partial x}\left(\mu \frac{\partial u}{\partial x}\right)+\frac{\partial}{\partial y}\left(\mu \frac{\partial u}{\partial y}\right) \\
& u \frac{\partial v}{\partial x}+v \frac{\partial v}{\partial y}=-\frac{1}{\rho} \frac{\partial p}{\partial y}+\frac{\partial}{\partial x}\left(\mu \frac{\partial v}{\partial x}\right)+\frac{\partial}{\partial y}\left(\mu \frac{\partial v}{\partial y}\right)-\rho \cdot g
\end{aligned}
$$

With Boussinesq approximations, the density is constant for all terms in the governing equations except for the bouncy force term that the density is a linear function of the temperature.

$\rho=\rho_{o}(1-\beta \Delta T)$

by introducing equation 5 into equation 4 yield:

$u \frac{\partial v}{\partial x}+v \frac{\partial v}{\partial y}=-\frac{1}{\rho} \frac{\partial p}{\partial x}+\frac{\partial}{\partial x}\left(\mu \frac{\partial v}{\partial x}\right)+\frac{\partial}{\partial y}\left(\mu \frac{\partial v}{\partial y}\right)+g \dot{\beta} \Delta T$

The stream function $(\psi)$ and vorticity $(\omega)$ in the governing equations are defined as follows:

$$
\begin{aligned}
& u=\frac{\partial \psi}{\partial y}, \quad v=-\frac{\partial \psi}{\partial x} \\
& \frac{\partial v}{\partial x}-\frac{\partial u}{\partial y}=\omega
\end{aligned}
$$

The stream function formulation satisfies continuity equation and by substituting them in equation 1 yield.

$$
\frac{\partial^{2} \psi}{\partial x^{2}}+\frac{\partial^{2} \psi}{\partial y^{2}}=-\omega
$$

By suitable manipulation, the pressure term in governing equations may be eliminated, then, 
$\frac{\partial \psi}{\partial y} \frac{\partial \omega}{\partial x}-\frac{\partial \psi}{\partial x} \frac{\partial \omega}{\partial y}=\frac{\partial}{\partial x}\left(\mu \frac{\partial \omega}{\partial x}\right)+\frac{\partial}{\partial y}\left(\mu \frac{\partial \omega}{\partial y}\right)+g \beta \frac{\partial T}{\partial x}$

Therefore the energy equation becomes.

$\frac{\partial \psi}{\partial y} \frac{\partial T}{\partial x}-\frac{\partial \psi}{\partial x} \frac{\partial T}{\partial y}=\frac{\partial}{\partial x}\left(\frac{\mu}{\operatorname{Pr}} \frac{\partial T}{\partial x}\right)+\frac{\partial}{\partial y}\left(\frac{\mu}{\operatorname{Pr}} \frac{\partial T}{\partial y}\right)$

The above equations are non-dimensionalized in order to identify the relevant dimensionless parameters influencing the problem of this work The variables are nondimensionalized by defining the following parameters:

$$
X=\frac{x}{L} \quad, Y=\frac{y}{L}, \phi=\frac{\psi}{\vartheta}, \theta=\frac{T-T_{c}}{T_{h}-T_{c}}, \Omega=\frac{\omega L^{2}}{\vartheta}, Y_{F}=\frac{Y_{l f}}{L}, L f=\frac{l_{f}}{L}
$$

The width of the enclosure (L) is the characteristics length in the problem. Using nondimensional variables defined above, the non-dimensional governing equations are obtained as:

\section{Energy Equation}

$\frac{\partial \phi}{\partial Y} \frac{\partial \theta}{\partial X}-\frac{\partial \phi}{\partial X} \frac{\partial \theta}{\partial Y}=\frac{1}{\operatorname{Pr}}\left(\frac{\partial^{2} \theta}{\partial X^{2}}+\frac{\partial^{2} \theta}{\partial Y^{2}}\right)$

\section{Momentum Equation}

$$
\frac{\partial \phi}{\partial Y} \frac{\partial \Omega}{\partial X}-\frac{\partial \phi}{\partial X} \frac{\partial \Omega}{\partial Y}=\frac{R a}{\operatorname{Pr}} \frac{\partial \theta}{\partial x}+\frac{\partial^{2} \Omega}{\partial X^{2}}+\frac{\partial^{2} \Omega}{\partial Y^{2}}
$$

\section{Continuity Equation}

$$
\frac{\partial^{2} \phi}{\partial X^{2}}+\frac{\partial^{2} \phi}{\partial Y^{2}}=-\Omega
$$

The Boundary conditions are:

$$
\begin{array}{ll}
\text { at } \quad X=0.0 \quad 0.0 \leq Y \leq 1.0 & \theta=1.0 \text {, and } \phi=0.0 \quad \& \Omega=0.0 \\
\text { at } \quad X=1.0 \quad 0.0 \leq Y \leq 1.0 & \theta=0.0 \text {, and } \phi=0.0 \quad \& \Omega=0.0 \\
\text { at } \quad 0.0 \leq X \leq L f \quad Y=Y_{F} & \theta=1.0 \text {, and } \phi=0.0 \quad \& \Omega=0.0 \\
\text { at } L-L f \leq X \leq L \quad Y=Y f \quad \theta=0.0 \text {, and } \phi=0.0 \quad \& \Omega=0.0 \\
\text { at } 0.0 \leq X \leq L \quad Y=0.0 \quad \frac{\partial \theta}{\partial Y}=0.0 \text {, and } \phi=0.0 \quad \& \Omega=0.0 \\
\text { at } 0.0 \leq X \leq L \quad Y=1.0 \quad \frac{\partial \theta}{\partial Y}=0.0 \text {, and } \phi=0.0 \quad \& \Omega=0.0
\end{array}
$$




\section{Numerical method}

The governing equations for steady state, laminar, two dimensional natural convection heat transfer in a square enclosure with perfectly conducting thin fins attached to the hot and cold walls are solved by using the finite difference technique It's procedure is based on the most common series, Taylor series .Using this series, all partial derivatives in governing partial equations are converted to forms that can be handled by computer.

The mesh consists of ( $m y)$ vertical and $(m x)$ horizontal lines positioned at intervals of $\Delta \mathrm{x}$ and $\Delta y$, respectively .Assuming that a function " $f$ " and its derivatives are single-valued, finite and continuous functions of the independent variables $x$ and $y$. Thus, the following finite difference formulas for the first and second order derivatives at grid point $(\mathrm{i}, \mathrm{j}$ ) from expansions of Taylor series had been obtained :

For interior points used central difference equations $(17,18)$, upper insulated surface used backward difference equation (20) and for lower insulated surface used forward difference equation (19).

$$
\begin{array}{lll}
\frac{\partial f}{\partial x}=\frac{f_{i+1, j}-f_{i-1, j}}{2 \Delta x}+O(\Delta x)^{2} & (\text { Central difference) } & \ldots 17 \\
\frac{\partial^{2} f}{\partial x^{2}}=\frac{f_{i-1, j}-2 f_{i, j}+f_{i+1, j}}{\Delta x^{2}}+O(\Delta x)^{2} & (\text { Central difference) } & \ldots 18 \\
\frac{\partial f}{\partial x}=\frac{-3 f_{i, j}+4 f_{i+1, j}-f_{i+2, j}}{2 \Delta x}+O(\Delta x)^{2} & \text { (Forward difference) } & \ldots 19 \\
\frac{\partial f}{\partial x}=\frac{3 f_{i, j}-4 f_{i-1, j}+f_{i-2, j}}{2 \Delta x}+O(\Delta x)^{2} & \text { (Backward difference) } & \ldots 20
\end{array}
$$

In the same way the derivatives in y-direction can be obtained.

Therefore, by substituting the above equations in the non-dimensional governing equations obtained previously, all temperatures, stream function and vorticity at each point can be obtained. The heat transfer from the walls of the enclosure can be obtained by using the integration of temperature gradient along the vertical wall of the enclosure:

$$
Q=\int_{0}^{1} \frac{\partial \theta}{\partial x} \hat{\partial}
$$

And along each fin:

$$
Q=\int_{0}^{L f} \frac{\partial \theta}{\partial y} \partial x
$$

After computing the total quantity of the heat transfer in the enclosure, Nusselt number can be calculated which equals the ratio between heat transfer by convection to the heat transfer by pure conduction:

$$
N u=\frac{Q_{\text {conv. }}}{Q_{\text {cond }}}
$$




\section{Result and Discussion}

In this section, numerical results for streamlines and temperature contours for various values of fins number, fins dimensionless length, and different value of Rayleigh number. All results are computed for a Prandtl number $\mathrm{Pr}=0.7$

Figure (2) A,B,C, represents the effect of Rayleigh number on steady state contour plots for the streamlines and isotherm lines for various values of Rayleigh number $\left(10^{3}, 10^{4}\right)$ for the three cases when the dimensionless fins length equal 0.45 with respect to the width of the enclosure. Generally it can be seen from the above figures that the increasing in the Rayleigh number causes increasing in temperature gradient along the vertical walls also the value of stream function increased with the increasing in the Rayleigh number, this because the buoyancy force increased with the increasing in the Rayleigh number, which represent the driving force in the natural convection heat transfer. Also it can be observed that increasing the number of fins which result in decreasing in temperature gradient as result of restriction to the fluid flow.

Figure (3) A, B, C, shows the effect of the increasing in the dimensionless fins length upon streamlines and isotherm lines for the three cases when Rayleigh number equals $2 \times 10^{3}$. the increasing in the dimensionless fins length cases decreasing in temperature gradient along the vertical walls as fin elongate restricted the fluid flow so the temperature gradient decreases. Also the increasing in the number of fins causing in decreasing the temperature gradient. Also the increasing in dimensionless fins length cases the appearance multi centers flow this situation resulting in efficient heat transfer process.

Figure (4) A, B, C, depicts the relation ship between the Nusselt number and Rayleigh number for different dimensionless fins length for the three cases. From the above figures it can be seen that the increasing in the Rayleigh number for the same length of fins causes increasing the Nusselt number due to more heat transfer by convection outcome from buoyancy force which increases the temperature gradient along the vertical surface and along the fins. The increasing in the dimensionless fins length will reduce the Nusselt number due to greater heat transfer by conduction over that by convection whereas the Nusselt number equal the ratio between the heat transfer by convection to the heat transfer by conduction. Also the more number of fins reduce the Nusselt number due to the drop in temperature gradient because the increasing in the dimensionless fins length causes in the restriction of the fluid flow.

\section{Conclusions.}

Heat transfer by natural convection inside enclosure with perfectly conducting thin fins has been numerically studied. The numerical simulation reveals the following conclusions:

1. The heat transfer by natural convection is increased with the higher Rayleigh number.

2. The Nusselt number and temperature gradient are increased as Rayleigh number be higher.

3. The Nusselt number and temperature gradient decreased with the elongation of fins.

4. The Nusselt number and temperature gradient decreased with more number of fins 

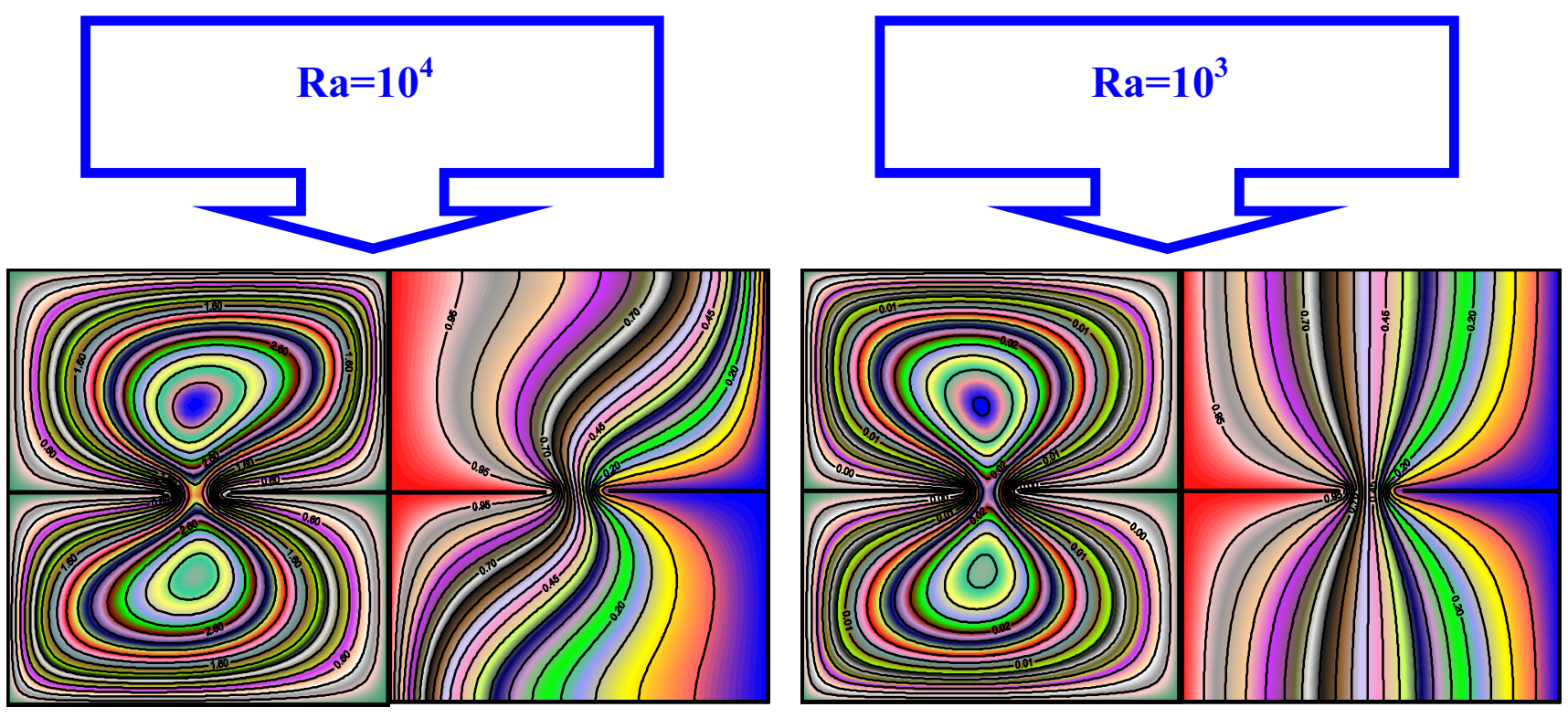

(A)
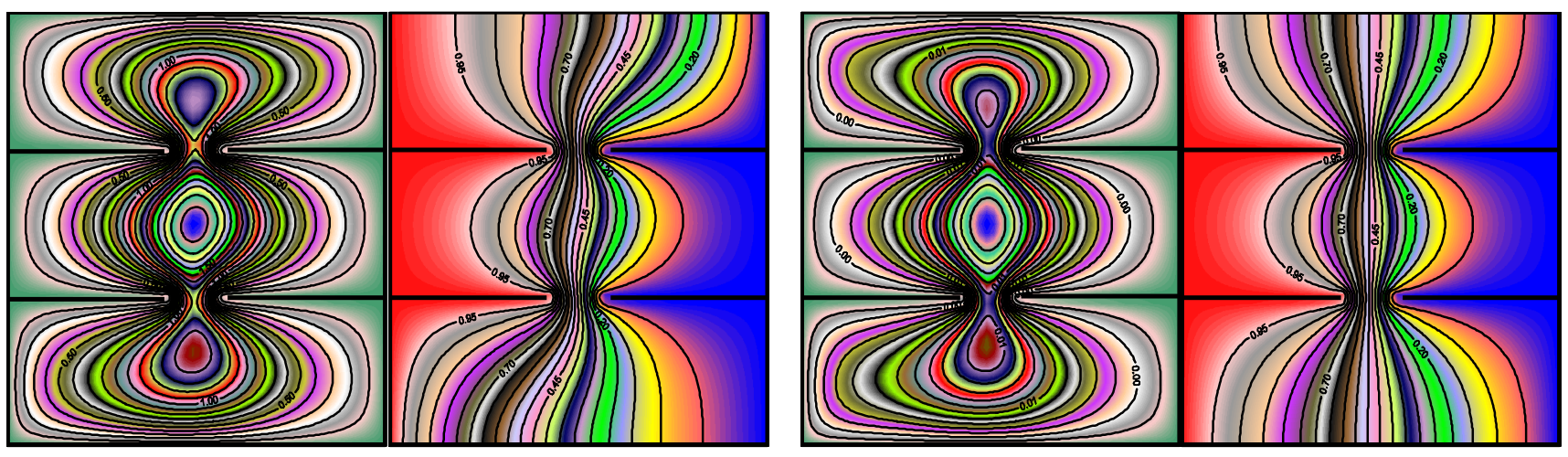

(B)
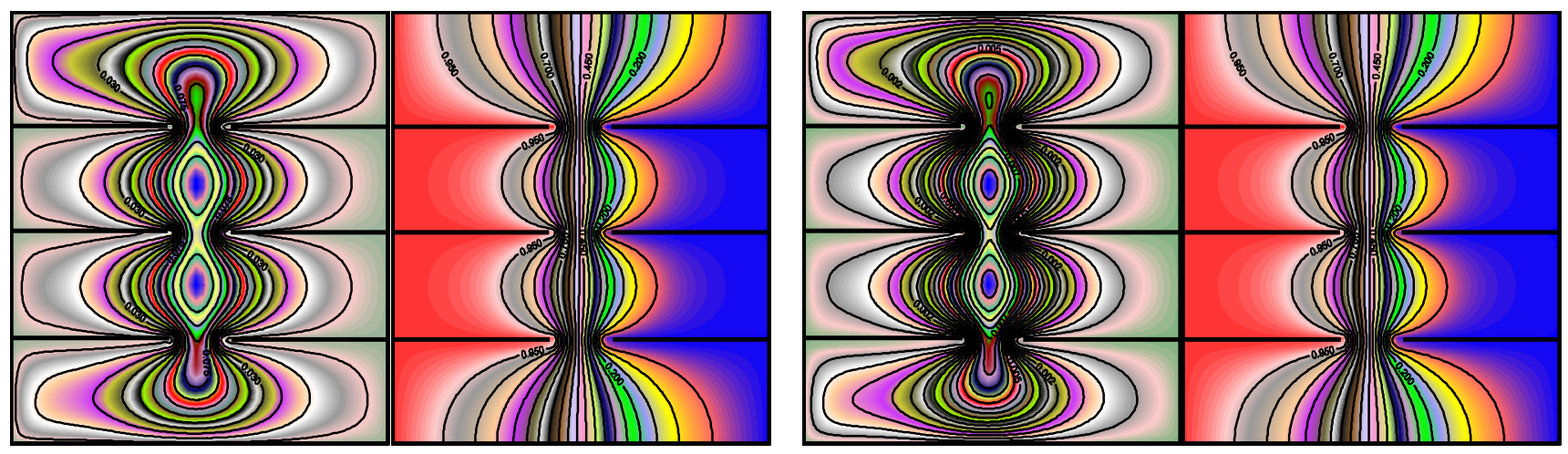

(C)

Fig.(2) effect of Rayleigh on temperature distribution and flow regime at length of fins $=0.45$, $A($ number of fins $=1), B($ number of fins $=2), C($ number of fins $=3)$ 

Al-Rafidain Engineering
Vol.18
No.1
January
2010
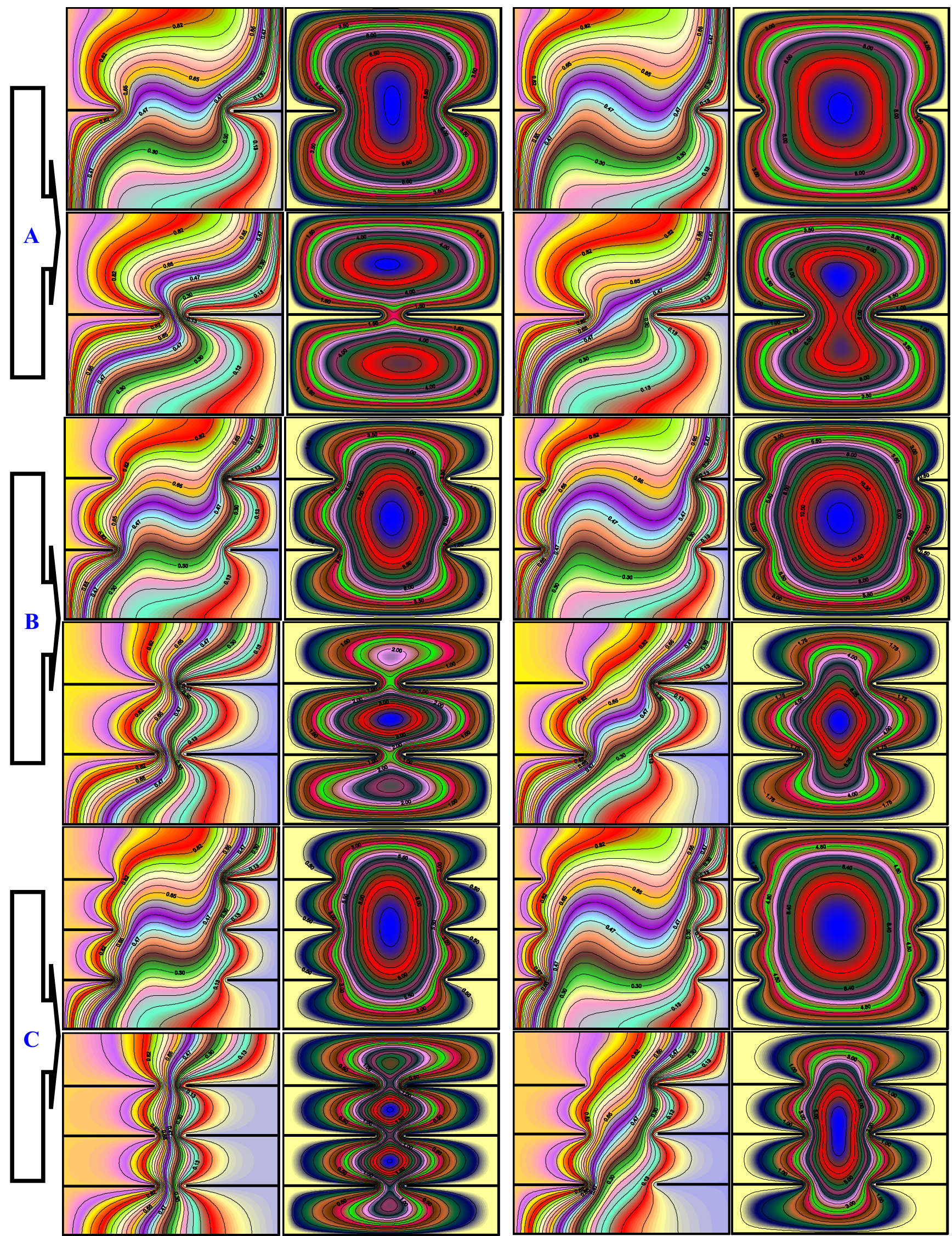

Fig.(3) effect of fins length $(0.15,0.25,0.35,0.45)$ on temperature distribution and flow regime at $R^{*}=2000, A($ number of fins $=1), B$ (number of fins $\left.=2\right), C($ number of fins $=3$ ) 


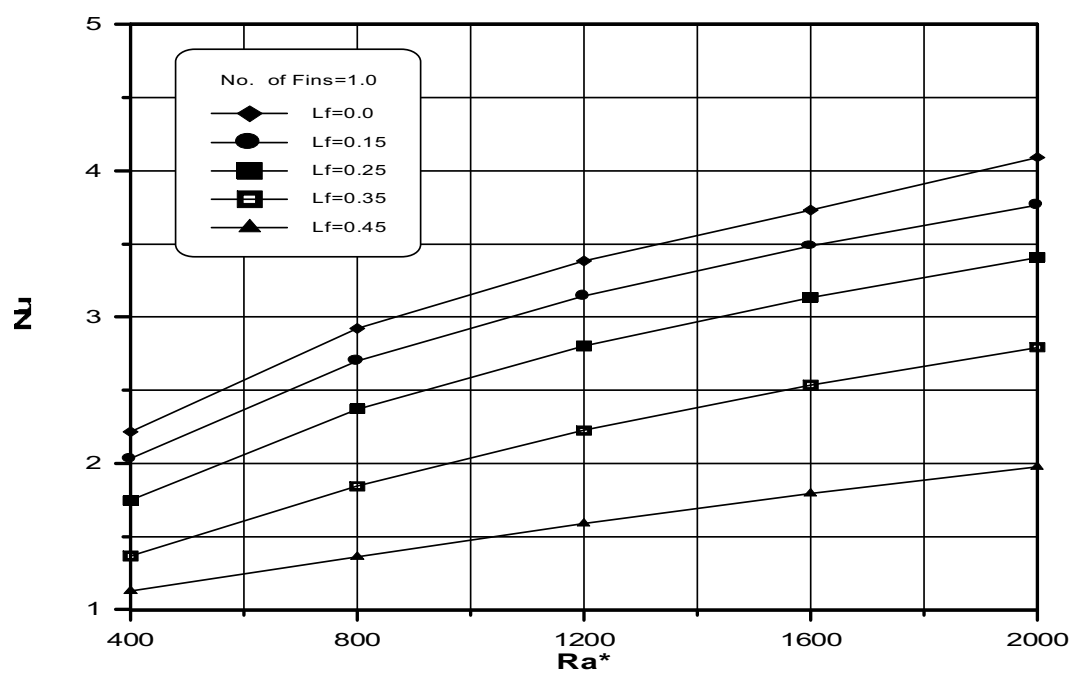

(A)

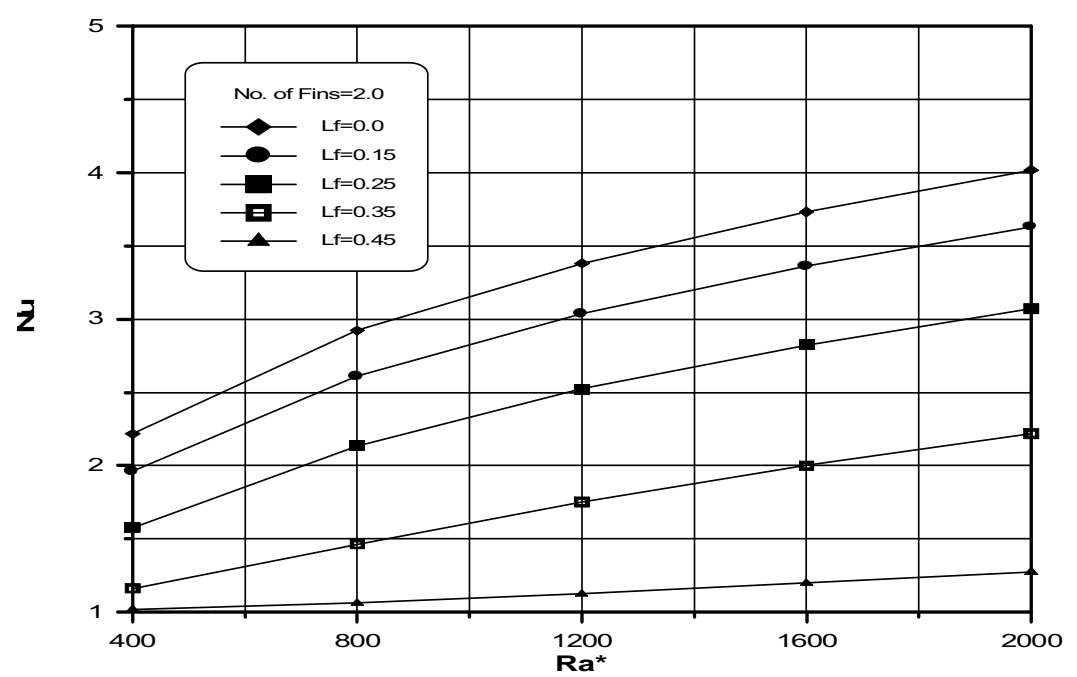

(B)

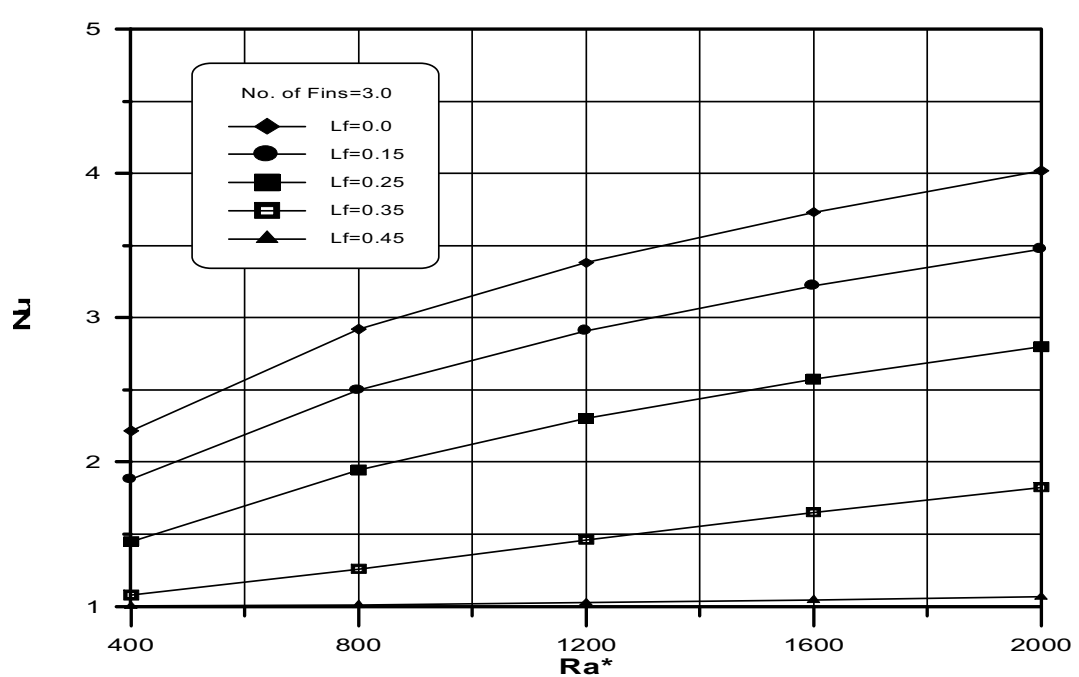

(C)

Fig.(4) variation of $\mathrm{Nu}$ with Ra, $\mathrm{A}$ (number of fins =1), B(number of fins =2), $\mathrm{C}($ number of fins $=3)$, 


\section{References}

1-Bejan A," Convection Heat Transfer" Wiley-Interscience Publication Joun Wiley \&Sons, Inc., 1984.

2-R.L. Frederick, "Natural convection in an inclined square enclosure with a partition attached to its cold wall", Int. J. Heat Mass Transfer 32 pp.87-94, 1989.

3-R.L. Frederick, A. Valencia, "Heat transfer in a square cavity with a conducting partition on its hot wall", Int. Commun. Heat Mass Transfer 16 pp.347-354, 1989

4-R.Scozia, R.L.Frederick, " Natural convection in slender cavities with multiple fins attached on an active wall ", Numer. Heat Transfer, Part A 20 pp.127-158. 1991

5-M. Hasnaoui, P. Vasseur, E. Bilgen,"Natural convection in rectangular enclosures with adiabatic fins attached on the heated wall", Warme and Stoffubertragung 27 pp.357-368. 1992

6-A. Nag, A. Sarkar, V.M.K. Sastri, "Natural convection in a differentially heated square cavity with a horizontal partition plate on the hot wall", Comput. Methods Appl. Mech. Engrg. 110 pp.143-156, 1993

7-E. K. Lakhal, M. Hasnaoui, E. Bilgen, P. Vasseur."Natural convection in Inclined rectangular enclosures with perfectly conducting fins attached on the heated wall" Heat and Mass Transfer pp.365-373 , 1997.

8-E. Bilgen, "Natural convection in enclosures with partial partitions", Renewable Energy 26 pp.257-270. 2002

9- X. Shi, J.M. Khodadadi, Laminar fluid flow and heat transfer in a liddriven cavity due to a thin fin, ASME J. Heat Transfer 124 (6) pp.1056-1063. 2002.

10-X. Shi, J.M. Khodadadi, Laminar natural convection heat transfer in a differentially heated square cavity due to a thin fin on the hot wall, ASME J. Heat Transfer 125 (4) pp. 624-634. 2003

11-E. Bilgen " Natural convection in cavities with a thin fin on the hot wall" International Journal of Heat and Mass Transfer 48 pp.3493-3505. 2005

12-A.Ben-Nakhi, A.Chamkha, "Effect of length and inclination of a thin fin on natural convection in a square enclosure",Numer. Heat Transfer Part A: Appl. 50(4) pp.389-407. 2006

13-Abdullatif Ben-Nakhi a,*, Ali J. Chamkha $\mathrm{b}$ " Conjugate natural convection in a square enclosure with inclined thin fin of arbitrary length" International Journal of Thermal Sciences 46 pp.467-478, 2007

14- M. Ghassemi , M. Pirmohammadi, Gh. A. Sheikhzadeh "A Numerical Study of Natural Convection in Tilted Cavity with Two Baffles Attached to its Isothermal Walls" Weas Transaction on Fluid Mechanics Issue 3, Vol. 2 July 2007.

15-Sivasankaran and Kandaswamy " Effect of Conductive Baffles on hot wall in Double Diffusive Convection of Water near density maximum" The Arabian Journal for Science and Engineering, Volume 32, Number 1B 37 April 2007.

16-Feng $\mathrm{Xu} *$, John C. Patterson, Chengwang Lei " An experimental study of the unsteady thermal flow around a thin fin on a sidewall of a differentially heated cavity" International Journal of Heat and Fluid Flow 29 pp.1139-1153. 2008

17-Mohammed Rabhi, Hicham Bouali, Ahmed Mezrhab* "Radiation-natural convection heat transfer in inclined rectangular enclosures with multiple partitions" Energy Conversion and Management 49 pp.1228-1236. 2008

$18-N$. Kasayapanand * "A computational fluid dynamics modeling of natural convection in finned enclosure under electric field" Applied Thermal Engineering 29 pp.131-141, 2009

19-Borse,G. J., FORTRAN77 and Numerical Method for Engineering, McGraw- Hill Book Company, Inc., 1985

$$
\text { تم اجراء البحث في كلية الهنذسة - جامعة الموصل }
$$

